\title{
ADMINISTRAÇÃO RURAL: UM ESTUDO DE CASO EM UMA EMPRESA RURAL FAMILIAR
}

Edilene Mayumi Murashita Takenaka, Éverton Correia Silva, Jane A. da Silva Tejada

Curso de Administração da Universidade do Oeste Paulista - UNOESTE. E-mail: edilene@unoeste.br

\section{RESUMO}

As propriedades rurais por muito tempo foram consideradas pelos proprietários como um meio de lazer, uma atividade de renda extra, ou uma forma de auto-sustentação. Nos dias atuais, essa propriedade rural deve ser administrada como uma empresa. Por isso, foi realizado um estudo de caso com uma abordagem qualitativa e coleta de dados através de pesquisa bibliográfica e pesquisa descritiva, através de entrevistas em uma propriedade rural familiar localizada no município de João Ramalho Estado de São Paulo, atuante no ramo de pecuária de corte. Esse estudo teve por objetivo, diagnosticar a real situação da empresa rural analisando no que se refere aos instrumentos da administração rural e oferecer alternativas de ação. Assim, consideramos a hipótese da presente pesquisa, que a empresa rural em questão necessita adotar preceitos da gestão administrativa em suas funções: planejar; organizar; dirigir e controlar, diante da evolução do papel da atividade pecuária no mercado atual.

Palavras-chave: Administração Rural Familiar. Agronegócio. Pecuária de Corte.

\section{INTRODUÇÃO}

A empresa familiar é considerada uma das organizações mais antigas da humanidade. Vários autores descrevem que o início das empresas familiares se deu na Mesopotâmia e no Egito, onde eram divididas parte de terras a membros das famílias que tinham como tarefa plantar, colher e pagar impostos ao governo.

A necessidade contínua de trocar um produto por outro, um serviço por outro, uniu as pessoas em pequenas comunidades, fazendo surgir o comércio. Esta foi a natureza das empresas durante centenas de anos, tanto aqui quanto no exterior.

No Brasil deu-se a origem após descobrimento e colonização por Portugal, período em que foram distribuídos lotes de terras (as chamadas capitanias hereditárias) e, após a morte dos capitães, as mesmas eram repassadas aos seus herdeiros. Assim, as empresas familiares foram se difundindo e ganhando espaço na zona rural e urbana, sendo consideradas como a grande maioria dos tipos de organizações no Brasil e até no mundo.

Para que uma empresa seja considerada familiar é necessário que membros desta família estejam gerindo e exercendo atividades há pelo menos duas gerações. Esses tipos de organizações apresentam varias características que devem ser consideradas, entre elas a dificuldade em separar o emocional e o racional. As decisões são centralizadas no fundador, promoção de pessoas sem 
qualificação baseado somente na confiança, a ocorrência de uma estrutura administrativa e operacional enxuta, entre outras características que serão descritas ao longo deste trabalho.

Importante acrescentar ainda, o fato de que muitos negócios familiares têm uma duração de vida reduzida, vítimas de problemas de sucessão familiar, cujo herdeiro não foi preparado e nem capacitado para assumir o cargo que lhe é de direito. As empresas familiares têm sido muito prejudicadas com a falta de critérios e objetivos para a sua modernização e a profissionalização dos seus sucessores.

Considerando esses atributos e também que o setor do agronegócio no Brasil encontra-se em plena expansão, é importante que as empresas rurais adotem medidas e ferramentas administrativas.

Deste modo, encontra-se a necessidade de realizar um estudo de caso em uma empresa rural familiar no município de João Ramalho, no interior do Estado de São Paulo, atuante no ramo da pecuária de corte, especificamente na cria de gado Nelore. Tal empresa está em atividades há mais de 80 anos (desde 1929) e a terceira geração da família é a responsável pela sua administração.

Atualmente, a empresa trabalha com a pecuária de corte voltada para a cria e recria de gado Nelore e possui apenas 1 funcionário para a função de serviços gerais. A gestão da empresa fica a cargo do atual proprietário. A sua esposa, um sobrinho, e uma filha e os outros quatro filhos estão exercendo outros tipos de atividades (comercial e prestação de serviços) fora da empresa.

Sendo assim, o objetivo geral desta pesquisa é diagnosticar a real situação da empresa rural analisando no que se refere aos instrumentos da administração rural e oferecer alternativas de ação.

Para tanto, a metodologia utilizada foi a pesquisa bibliográfica, seguida de um estudo de caso em uma empresa familiar rural no município de João Ramalho interior do Estado de São Paulo, com uma abordagem qualitativa, a partir da coleta de dados através de uma entrevista com o proprietário da empresa pesquisada e observação participante, já que um dos pesquisadores atua na empresa de maneira ativa.

\section{ADMINISTRAÇÃO NA EMPRESA RURAL}

A Empresa rural é uma atividade econômica que se dá através de meios utilizados pela produtividade da terra. Esse campo de atuação está se desenvolvendo cada vez mais devido ao crescimento econômico e extenso território que nosso país possui. 
Porém, podemos observar que por falta de conhecimentos administrativos certas empresas desses setores ficam estagnadas no mercado. Por isso, se faz necessário que esses produtores rurais procurem aplicar e praticar processos administrativos em sua empresa.

De acordo com Noronha (1940, p. 23):

No Brasil a maioria das fazendas é administrada pelo proprietário e sua família. Entretanto, as expressões empresa rural e empresa agrícola são encontradas com frequência na literatura no sentido de fazenda, propriedade agrícola ou estabelecimento agropecuário, organizado com finalidade de produção comercial. Propriedades agrícolas destinadas ao lazer, à experimentação ou para fins de ensino não são consideradas empresas rurais.

Percebemos que é importante reconhecer as diferenças entre empresas rurais e as demais, porque as empresas rurais trabalham com sistema de produção, mão de obra familiar e o trabalho administrativo do proprietário.

Conforme Callado (2006, p. 56), "facilmente, pode-se constatar que, embora não seja verdade absoluta, a administração das empresas ligadas ao agronegócio brasileiro ainda se desenvolve dentro de critérios tradicionais". Nas palavras do autor, é possível entender que algumas propriedades rurais não utilizam novos métodos e ferramentas administrativas, pelo simples fato de não possuir esses conhecimentos, já que muitos proprietários trabalham de forma atrasada.

De acordo com estudos realizados por Callado (2006, p. 4):

A importância da apropriação de práticas administrativas sistêmicas dentro dos negócios agroindustriais é comentada por Farina (2000), que evidencia as relações entre os segmentos componentes de uma cadeia produtiva relativamente aos padrões de concorrência, crescimento e competividade.

Levando-se em conta o que foi ressaltado, entende-se que o conhecimento amplo nos negócios agroindustriais é de suma importância para gerenciar e organizar o processo administrativo de uma empresa. As técnicas administrativas são fundamentais. Com ela, se criam procedimentos, avaliações e informações que possibilitam o controle geral do negócio, bem como um meio para cumprir os fins produtivos da empresa neste mercado competitivo. (FRITZ, 1993)

Para Noronha (1940, p. 25), "ao longo do processo de crescimento da empresa, o administrador defronta-se com pelo menos cinco áreas de tomada de decisão: investimento, produção, comercialização, finanças e consumo". Neste sentido, entende-se que seja necessário 
que o administrador possua conhecimentos técnicos e o mesmo, esteja preparado para saber tomar a devidas decisões, que são as características de um administrador.

No dizer expressivo de Silva (2012, p. 93), “administração é um dos mais críticos elementos do sucesso ou fracasso de qualquer empresa, inclusive da empresa rural. Sem uma administração efetiva, não haverá condições de atingir os objetivos". De acordo com o autor, podemos entender que o ato de administrar uma empresa requer grande comprometimento do administrador, por isso é necessário ter o conhecimento teórico e prático das ferramentas que a administração pode fornecer para enfrentar as dificuldades que poderão ocorrer em qualquer etapa da empresa.

\section{RESULTADOS}

Para apresentação e análise dos dados, foi elaborado um roteiro de entrevista que foi realizado diretamente com o proprietário da empresa analisada.

A empresa em questão é uma propriedade rural familiar que atua no ramo de pecuária de corte, especificamente na cria e recria de gado Nelore, que está situada na cidade de João Ramalho, interior do Estado de São Paulo.

Para esta análise, foram elaboradas vinte e uma perguntas que serviram de amostragem para identificar a real situação administrativa da empresa pesquisada.

As primeiras dificuldades assinaladas foram que no início não existiam os recursos e as tecnologias que temos hoje. Porém, nos dias atuais, mesmo tendo esses avanços a falta de incentivo atual do setor e o apoio familiar vêm dificultando a expansão e administração da empresa.

Sobre a posição da empresa no mercado atual, foi dita como estável. Apenas sobrevive e consegue se sobressair quando o mercado valoriza mais a produção agropecuária, neste caso, vendendo mais produtos por preço mais justo. Outro assunto abordado foram às decisões da empresa, que são tomadas de forma única pelo proprietário e desta forma, o mesmo nos relata uma dificuldade em tomar decisões.

Referente a divisões de cargos, o diretor relata que não tem divisão e todos podem opinar o que denota falta de direção, sendo necessário delegar cargos a todos que usufruam da propriedade.

Outro agravante apresentado nesta entrevista foi, à falta de controle financeiro, sendo imprescindível implantar processos e regras nas entradas e saídas de dinheiro da empresa. Fica complicado analisar a real situação do negócio, através de relatório como fluxo de caixa, para 
saber como andam os gastos e seus rendimentos. Podemos entender que o diretor utiliza métodos antigos para administrar sua empresa, precisando administrar de forma mais profissional e menos intuitiva.

Em relação às tarefas desenvolvidas pela empresa, o proprietário passa direto para seu subordinado conforme à necessidade sem nenhum planejamento. A contratação de novos funcionários é realizada à medida que surge a necessidade de novos serviços (por diárias) sendo feito sem critérios e métodos, o que contribui para ambos os problemas refletir no crescimento da empresa.

O proprietário da empresa disse que tem dificuldades na forma de administrar, porém não soube detalhar quais motivos e também observou não possuir conhecimentos teóricos e práticos das ferramentas administrativas rurais. Porém, o diretor ressaltou que acredita que com esses conhecimentos que não contém e se aplicado em seus processos sua empresa tende a melhorar, ratificando a vontade de aperfeiçoar a sua administração.

Em virtude da expansão do agronegócio e o forte crescimento econômico de nosso país, foi perguntado ao proprietário da empresa à possibilidade de contratar um profissional de administração, para aperfeiçoar e aprimorar seus processos administrativos, a fim de crescer no mercado. O proprietário respondeu, que não, porque o administrador seria ele mesmo e teria um gasto a mais para contratar este profissional e no momento não tem condição de arcar com este custo.

A produção da empresa é feita sem nenhum tipo de controle; os métodos utilizados são os meios naturais considerando os reprodutores (touro e vaca) como máquinas, a venda é realizada no período das vacinações em Maio e Novembro, onde são separados bezerros de 8 a 12 meses e vendidos. Mas, nunca o proprietário quantos bezerros terá, não existe identificação entre as matrizes para saber se estão produzindo ou não, e nem controle de natalidade. Os lotes que são comercializados são cada um de uma idade, pois existe uma variação de quatro meses, o que dificulta na comercialização, pois cada um valeria um preço.

O diretor da empresa demostra empenho em melhorar sua gestão, mas a falta de dinheiro e a extensão de terra o dificultam a conduzir da maneira que acredita ser a melhor. A necessidade do momento o faz administrar a empresa sem parâmetros, o que acaba levando para caminhos com muitos obstáculos. Na questão de comercialização dos produtos vendidos, existe sim um planejamento quando surge oportunidade ou necessidade. 
A respeito de novas informações, o diretor da empresa cita buscar conhecimentos de matrizes e reprodutores de qualidade para suprir suas necessidades através de produtos veterinários de procedências e dentro das normas brasileiras. O ponto positivo que a empresa possui são seus recursos e suas matérias-primas de qualidade. O ponto negativo apontado pelo proprietário é a falta pastagem, principalmente em épocas da seca, o que dificulta o desenvolvimento do gado, já que o meio de alimentação com menor custo é a pastagem, e, na falta de alimentos para o gado, tem que comprar ração para que ele não perca peso ou até mesmo morra de fome.

Nesta entrevista foi abordado também, se há um controle de custo separado de pessoa física e pessoa jurídica. O diretor expõe que não existe este controle separado em sua empresa, o que acaba prejudicando e deixando inviável a realização de análise e projeções financeiras da mesma. É indispensável a separação desses gastos para aprimoramento dos processos administrativos e futuras análises financeiras da empresa pesquisada.

\section{DISCUSSÃO}

Identificamos a falta da utilização das ferramentas administrativas em diversos processos da propriedade rural, sendo que o proprietário tem como dever analisar e comandar vários fatores da empresa, como a terra, maquinários, insumos e mão de obra. Para isso, sugerimos ao proprietário algumas medidas a serem tomadas, mesmo que sendo uma empresa pequena, existe a necessidade de se adequar a administração nas seguintes áreas.

RECURSOS HUMANOS: é importante que se criem políticas de recursos humanos; planejamento e contração de novos funcionários; delegação das funções de cada um dentro da empresa; assim como a criação de um organograma. Respeitar cada cargo em sua devida posição, para não ocorrer o risco de comunicação errada; criação de metas a serem alcançadas e com o alcance receber gratificações.

PRODUÇÃO: através de ferramentas administrativas como planejar; organizar; controlar e dirigir é possível fazer a empresa caminhar em busca de um crescimento. Sendo assim, é possível estabelecer um número de bezerros anuais como meta; controlar a natalidade dos bezerros, assim com a fertilidade das vacas pelos meios de identificação, podendo se manual através de brincos e tabelas ou eletrônicos com chip; padronizar as idades de todos os bezerros através da estação de monta; fazer um levantamento de custos da produção e encontrar o ponto 
de equilíbrio, assim como planejado na época de venda, aonde se consegue alcançar maiores valores nos bezerros.

Para isso, também, é necessário realizar renovação de pastagem, com tipos de pastos que consigam superar melhor a época de seca (Junho a Agosto), e também o manejo de pastagem. Fazer projeções de quanto cada operação custará, para ver se tem dinheiro em caixa suficiente. É necessário programar a compra de insumos e produtos veterinários.

FINANCEIRO: A empresas necessitam adotar meios de relatórios contábeis, para registrar a vida financeira da empresa já que foi identificado como um dos pontos mais fracos da empresa o controle financeiro, como por exemplo, o fluxo de caixa; balanço patrimonial e demonstração de resultados; assim como a divisão de receitas e despesas do sítio das demais, podem ser realizados esses relatórios com a ajuda de softwares gratuito disponibilizados na internet.

COMERCIAL: A área comercial desta empresa tem que ficar atualizada com o valor de mercado, já que é um setor em que sempre sofre variação. É Preciso ter conhecimento de ferramentas que facilitem o acesso deste preço que modifica de acordo com o mercado e o clima de nosso país e dos países concorrentes que também comercializam bovinos.

\section{CONSIDERAÇÕES FINAIS}

Concluímos que a empresa rural analisada é gerida por um proprietário que desconhece práticas e processos administrativos no campo da administração como ciência. Entretanto, sempre se baseou em conhecimentos adquiridos ao longo do tempo durante o acompanhamento de seus antecessores na prática da gestão da empresa rural.

Como não foi realizado um estudo financeiro, porque a mesma não possui nenhum tipo de relatório contábil, não foi possível verificar se a empresa está tendo lucro ou prejuízo, já que também utiliza de outras receitas como casas de aluguel e aposentadorias para pagar os compromissos tanto o pessoal como jurídico.

Neste estudo também sugerimos um organograma, porque a empresa não possui. Nele foram estabelecidas áreas e funções a serem desempenhadas em conjunto com o proprietário e assim distribuir e otimizar os processos da empresa não sobrecarregando apenas uma pessoa.

Este trabalho foi elaborado com o intuito de mostrar a importância que tem a Administração e suas ferramentas nas organizações, sejam elas grandes corporações ou pequenas. 
Neste caso especificamente uma empresa rural familiar, necessitando a utilização dos preceitos administrativos para se desenvolver e crescer em um mercado cada vez mais competitivo.

\section{REFERÊNCIAS}

CAlLAdO, A. A. C. Agronegócio. São Paulo: Atlas, 2006.

FRITZ, R. Empresa familiar: uma visão empreendedora. São Paulo: Makron Books, 1993.

NORONHA, J. F. Projetos agropecuários: administração financeira, orçamento e viabilidade econômica. 2 ed. São Paulo: Atlas, 1987.

SILVA, R. A. G. Administração rural: teoria e prática. Curitiba: Juruá, 2012. 